\title{
The Integration of Nature-Based Solutions into Climate Adaptation Policy and Planning in Bangladesh
}

\section{$\underline{\text { Samina Islam }}^{1}$, Farah Anzum $^{2}$, Adiba Bintey Kamal ${ }^{1}$, Mahmuda Akter ${ }^{1}$, Ali Mohammad Rezaie ${ }^{1}$, Mizan R. Khan ${ }^{1}$}

${ }^{1}$ International Centre for Climate Change and Development (ICCCAD), Independent University Bangladesh, Dhaka, Bangladesh

${ }^{2}$ Independent Researcher, Dhaka, Bangladesh

https://doi.org/10.38126/ISPG180204

Corresponding author: samina.islam@icccad.org

Keywords: national policies; climate change; ecosystem-based adaptation; ecosystem services

Executive Summary: Bangladesh is regarded as one of the most climate-vulnerable regions in South Asia due to its unique geographical location and socio-economic conditions. Natural disasters, changing temperatures, precipitation, and sea level rise have affected agricultural production, infrastructure, and livelihoods in the country. To face these challenges, naturebased solutions ( $\mathrm{NbS}$ ) can address climate change adaptation, protection and management of natural ecosystems, and biodiversity conservation. For example, in Bangladesh, coastal mangroves can protect communities from storm surge and sea level rise, forests in hilly regions can prevent landslides, and green spaces in urban areas can reduce heat stress and promote the well-being of inhabitants. However, effective design, implementation, and upscaling of $\mathrm{NbS}$ requires support from national policies and plans.

This study reviews relevant Bangladeshi national policies from the past three decades to investigate $\mathrm{NbS}$ as a potential framework to address climate change and societal challenges in the country. We systematically analyzed twenty policy documents across three sectors: national development; disaster management and climate change; and environment and forest. Our study found growing emphasis on preservation, protection, and management of natural ecosystems in the national policies. However, our analysis showed that among the twenty policies, nineteen of them have no direct mention of NbS terminology. Instead, the policies include various strategies and terminologies that fall under the NbS umbrella, such as ecosystem-based adaptation, ecosystem services, and green and eco-building. However, these policies are still widely missing specific implementation guidelines, robust financial support, and institutional mechanisms for monitoring and evaluating $\mathrm{NbS}$ initiatives in Bangladesh. We recommend several policy actions to facilitate effective and inclusive $\mathrm{NbS}$ interventions in Bangladesh: enhance inter-ministry cooperation; develop national funding support; develop a national promotional campaign; pursue evidence-based research and capacity-building activities; and involve youth, marginalized people, and women. These actions can optimize the benefits of $\mathrm{NbS}$ to enhance the country's resilience against climate change and foster sustainable development.

\section{Introduction}

Due to its geographic, demographic, and socioeconomic conditions, Bangladesh is particularly susceptible to the adverse impacts of climate change.
According to the 2020 Global Climate Risk Index, Bangladesh stands at the seventh position among countries most affected by extreme weather events in the twenty-year period from 1999 through 2018 
(Eckstein, et al. 2019). The country's freshwater, agricultural resources, and coastal infrastructure are particularly vulnerable to the changing temperatures, precipitation, and sea level rise that amplify the impacts of climate change in Bangladesh (USAID 2013; Islam and Nursey-Bray 2017; Mondal et al. 2019). Climate change is also exacerbating socioeconomic vulnerabilities by adversely affecting lowincome agriculture and aquaculture sectors, which depend on seasonal climate conditions (Mondal, et al. 2019). A recent government report found that $80 \%$ of farmers in the country acknowledged changes in climate, with more than half of the respondents reporting that their agricultural land had been adversely affected by floods, droughts, and cyclones in the previous five years (MoFA 2018). In addition to crop production, the fisheries sector is also vulnerable to the effects of climate change-cyclones and storm surges can damage aquaculture infrastructure and increase unemployment (MoFA 2018). Therefore, Bangladesh needs to address these challenges by keeping nature at the core of its climate adaptation response. Nature-based solutions (NbS) can address these complexities and promote sustainable development for the future of the country.

$\mathrm{NbS}$ broadly describes nature-oriented actions that address societal issues, such as food and water insecurity, natural disasters, poverty, and public health. NbS emerged as an integrated approach in the early 2000s to sustainably manage natural and modified ecosystems, which contributes to nature conservation and ensures socio-economic benefits to communities (Cohen-Shacham, et al. 2016). Studies have also framed $\mathrm{NbS}$ as an umbrella concept that incorporates ecological restoration, ecosystem-based adaptation (EbA), green infrastructure, and integrated coastal zone management (CohenShacham, et al. 2019; Pauleit, et al. 2017). However, studies of $\mathrm{NbS}$ - which range from minimal intervention in existing ecosystems to the design and management of new ecosystems - demonstrate the emerging concept is still developing, and the terminology may not be widely used by decisionmakers and practitioners (Almenar, et al. 2021; Cohen-Shacham, et al. 2016; Eggermont, et al. 2015; European Commission 2015).

Existing case studies of NbS illustrate the potential of such strategies around the world. Coastal wetlands in the United States protect communities from storm surge and sea level rise and create economic stimulus by reducing flood insurance (Rezaie, et al. 2020). In Uruguay, coastal ecosystem restoration can reduce storm surge, coastal erosion, and inundation (Carro, et al. 2018). Another study on Burkina Faso indicates that protection of tropical forests can conserve water quality (Zongo, et al. 2017). In India, preserving mangroves provides protection from wind damage, storm surge, and coastal erosion (Badola and Hussain 2005).

Bangladesh, a developing county which is highly dependent on its natural resources for livelihood options, has practiced NbS informally to adapt to challenging climates. For example, the floating agricultural garden practice is well-known in SouthCentral Bangladesh, where $50 \%$ of the region is submerged under water (Irfanullah, et al. 2011). The local farmers apply indigenous knowledge to build "floating gardens" from local materials to grow crops and reduce food crises during the flood seasons (Alam and Chowdhury 2018). Bangladesh has also implemented large-scale coastal afforestation programs to reduce the impacts of storm surge and sea level rise (Rezaie, et al. 2019). The coastal forest areas, particularly the Sundarban Mangrove Forest, also play an instrumental role in carbon sequestration (Kibria 2014). However, even though select nature-based practices are already wellestablished, the potential of $\mathrm{NbS}$ in Bangladesh has not been translated into comprehensive policy action.

National policies in Bangladesh need to support the initiation, execution, and upscaling of $\mathrm{NbS}$ to address societal challenges (Cohen-Shacham, et al. 2019). While several national policies emphasize the importance of natural ecosystems for disaster management and climate change, they do not specifically address the implementation and monitoring of NbS (Tasnim, et al. 2020). Instead, the policies refer to a suite of various NbS-related approaches to mitigate climate change risks. In this study, we analyze national (1) development, (2) climate change and disaster management, and (3) environmental, forestry and biodiversity policy documents across three decades to understand the development and current state of $\mathrm{NbS}$ and related concepts in national policy discourse. We also present several policy insights and propose recommendations to further incorporate $\mathrm{NbS}$ into national policies to address climate change for the future of Bangladesh. 


\section{Methodology}

The study entails a systematic analysis of twenty Bangladeshi national policy documents dated from 1992 to 2020 (Table 1). We focused on long- and short-term national development, climate change, disaster management, and environmental and biodiversity policies to understand the role of $\mathrm{NbS}$ in these policies to address climate change risks in the country.
We approached $\mathrm{NbS}$ as an umbrella term (Seddon, et al. 2021) and searched for the following keywords to analyze the policies: "nature-based solutions;" "ecosystem;" "ecosystem-based adaptation"; "green infrastructure;" and "ecosystem services." We also included the keyword "disaster management" to examine whether the aforementioned approaches were considered as tools for addressing climate change and disaster management.

\begin{tabular}{|c|c|}
\hline National Sector & Policies \\
\hline Development & $\begin{array}{ll} & \text { Seventh Five Year Plan (2015) } \\
\circ & \text { Bangladesh Country Investment Plan for Environment, Forest and Climate } \\
& \text { Change (2017) } \\
\circ & \text { Bangladesh Delta Plan } 2100(2018) \\
\circ & \text { Perspective Plan } 2021-2041(2020) \\
\circ & \text { Eighth Five Year Plan }(2020)\end{array}$ \\
\hline $\begin{array}{l}\text { Climate Change and } \\
\text { Disaster Management }\end{array}$ & $\begin{array}{ll} & \text { Bangladesh Climate Change Strategy and Action Plan (2009) } \\
\circ & \text { National Adaptation Program of Action (2009) } \\
\circ & \text { Climate Change and Gender Action Plan (2013) } \\
\circ & \text { Intended Nationally Determined Contributions (2015) } \\
\circ & \text { The National Plan for Disaster Management (2017) } \\
\circ & \text { Nationally Determined Contributions (2020) } \\
\end{array}$ \\
\hline $\begin{array}{l}\text { Environment and } \\
\text { Biodiversity }\end{array}$ & $\begin{array}{ll}\circ & \text { National Environmental Policy (1992) } \\
\circ & \text { National Forest Policy (1994) } \\
\circ & \text { National Environmental Management Action Plan (1995) } \\
\circ & \text { Environment Conservation Act (1995) } \\
\circ & \text { Environment Conservation Rule (1997) } \\
\circ & \text { Revised National Forestry Policy (2016) } \\
\circ & \text { National Biodiversity Strategy and Action Plan of Bangladesh (2016) } \\
\circ & \text { Bangladesh Biodiversity Act (2017) } \\
\circ & \text { Revised National Environment Policy (2018) }\end{array}$ \\
\hline
\end{tabular}

Table 1: List of analyzed national policies identified across three sectors

III. NbS in the national policy discourse of Bangladesh

In this section, we present brief reviews of national policies across three sectors of Bangladesh to contextualize $\mathrm{NbS}$ in the historic policy discourse of Bangladesh (Table 1). Notably, most of these policies and acts were passed by the Bangladesh National Parliament, making them obligatory under the force of law. However, while citizens and economic agents can be penalized under these policies, the government is not necessarily held accountable if policies are not implemented or goals are not met.

\section{i. $N b S$ in national development policies}

Five long- and short-term national development policies establish the context of NbS in the country's development sector (Figure1). 


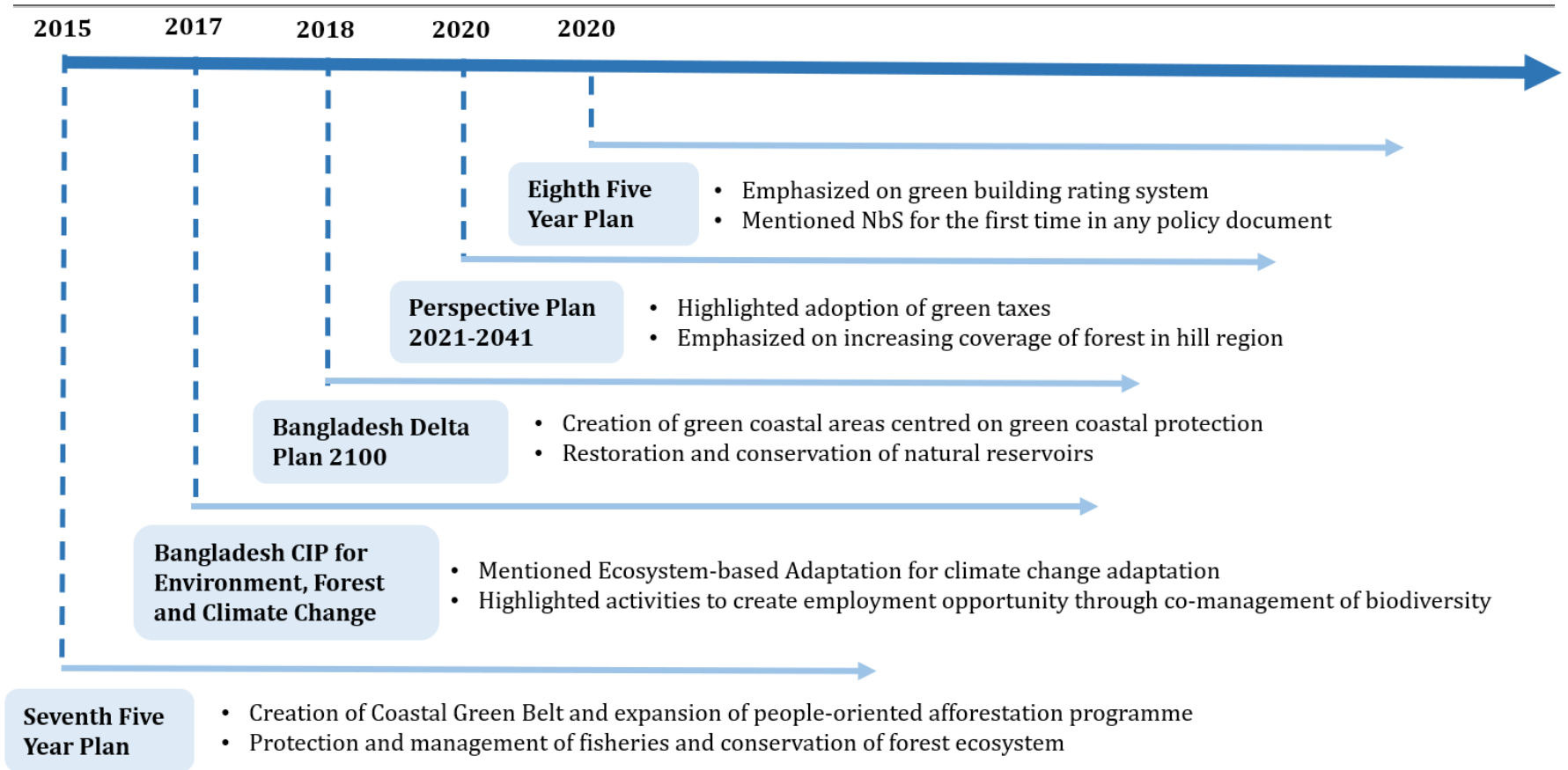

Figure 1: Timeline of national development policies

Seventh Five Year Plan (2015)

The Seventh Five Year Plan (7FYP) was published in 2015 by the General Economics Division of the Bangladesh Planning Commission. It aimed to develop strategies, policies, and institutions to accelerate job creation, reduce poverty, and meet Sustainable Development Goal targets. This document was a sequel to the Sixth Five Year Plan (FY2011-2015) aimed at completing the agenda of social and economic outcomes of the Perspective Plan of Bangladesh. The major targets of this plan focused on income and poverty, macroeconomic development, urban and human resource development, information and communication technologies, water and sanitation, energy and infrastructure, environmental sustainability, gender equality, and social protection (GED 2015).

The plan provided guidance for the government to sustainably use natural resources and maintain food security, and for concerned institutions, stakeholders, and parties to implement them. For example, the plan suggested, while offering limited details, removing trees that are detrimental to the environment to preserve forest ecosystems and protect endangered species of flora and fauna. The plan also highlighted expanding development of the Coastal Green Belt to reduce disaster risk and increase tree coverage along the coastline. In order to enhance biodiversity conservation and improve the quality of forestry, the plan emphasized afforestation and reforestation activities in the country. The plan also focused on inclusive governance through expansion of a people-oriented afforestation program for poverty alleviation and employment opportunities. Additionally, in order to make cities more sustainable, the plan encouraged measures to "incorporate and introduce Green Building Code in the National Building Code to have energy efficient buildings to address climate change" (GED 2015). The recently updated National Building Code now includes a chapter on "energy efficiency and sustainability" which encourages sustainable construction practices and explains the concept of environmentally-friendly building designs (Bhattacharjee 2021). Protection and management of the fisheries was also among the suggested actions to address food security in the country (GED 2015).

Therefore, the 7FYP addressed multiple factors related to $\mathrm{NbS}$ for planning and practices, though there was no direct mention of the term in this crucial document. At present, several of the specified plans have been successful, including poverty alleviation, economic development, significant progress on food security, improved rural infrastructure, and better sanitation facilities (Alam 2019). 
Bangladesh Country Investment Plan for Environment, Forest and Climate Change (2017)

The Bangladesh Country Investment Plan (CIP) for Environment, Forest, and Climate Change (EFCC) aimed to increase the contribution of EFCC sectors to national sustainable development through proper investment. The plan included enhanced provision of ecosystem services, thereby reducing poverty, improving environmental and human health benefits, and increasing resilience to climate change (MoEF 2017). The plan highlighted a variety of ecosystem services from nine main sources. For instance, coastal ecosystem services range between food, timber, climate regulation, storm and wave protection, and ecotourism. The EFCC CIP also mentioned EbA, which it defined as the use of biodiversity and ecosystem services to help people adapt to the adverse effects of climate change (MoEF 2017).

The policy highlighted that the loss of ecosystem services can lead to financial losses (MoEF 2017). The plan set several strategic priority areas for investment, which included sustainable forest management (social forestry, afforestation, reforestation, coastal belt development), biodiversity conservation (conservation of protected areas and endangered species), and sustainable management of wetlands, rivers, and marine ecosystems, among others. These actions would further create employment opportunities for rural communities and allow them to benefit economically from the improved co-management of biodiversity-enriched areas (MoEF 2017).

The strategies outlined in the EFCC CIP for enhancing biodiversity and human well-being (employment generation) through sustainable management and conservation of natural resources aligns with the objectives of $\mathrm{NbS}$. However, the plan did not explicitly use the term NbS; it instead used the term EbA, which is a vital component of the broader NbS umbrella.

\section{Bangladesh Delta Plan 2100 (2018)}

Bangladesh Delta Plan (BDP) 2100 is a long-term development plan to address challenges related to climate change in the Bangladesh Delta. The plan highlights the need for climate resilient ecosystem services (GED 2018). The plan focuses on agriculture and nature-based management strategies rather than infrastructure as a short-term adaptation strategy. For the medium-term, the plan suggests implementing land and water management practices, such as green coastal protection, flood resilient habitats, natural reservoir restoration and conservation (GED 2018). Though the plan does not mention $\mathrm{NbS}$; several elements of $\mathrm{NbS}$, such as nature-based management strategies for adaptation, green coastal protection, and conservation of natural reservoirs, were included.

\section{Perspective Plan 2021-2041 (2020)}

The Perspective Plan (PP) 2021-2041, also known as Vision 2041, sought to eliminate extreme poverty and elevate the country's status to an upper-middleincome country by 2031 and high-income country by 2041. Conservation of land productivity and forest resources, and improvement of biodiversity and ecosystem services, were some of the key aspirations of Vision 2041. It also highlighted the adoption of green taxes (carbon taxes) as a highly effective policy for regulating polluters by discouraging the consumption of carbon dioxide-emitting fossil fuels (GED 2020a).

The plan takes steps to increase the forest coverage in hilly regions and protect the environment and biodiversity to reduce poverty. However, there were no definitive guidelines on how conservation of natural resources and improvement of biodiversity can lead to income generation and poverty reduction.

\section{Eighth Five Year Plan (2020)}

The Eighth Five Year Plan (8FYP) was published in 2020 to promote prosperity and foster inclusiveness. The plan emphasized the development and management of water resources in the Chittagong Hill Tracts, which include creating green belt and ecofriendly structures for erosion management and restoring and protecting water-related ecosystems (GED 2020b). Priority was also given to the adoption and creation of a "green building rating system" which would allow assessment of buildings against a set of criteria and recognition of their environmental performance (GED 2020b). Importantly, NbS was mentioned explicitly in the 8FYP - the first time in a Bangladeshi policy document. Though the plan did not provide any definition, guidelines, or strategies, it prioritized $\mathrm{NbS}$ in the upcoming National Adaptation Plan (NAP) of Bangladesh (GED 2020b). 
ii. NbS in climate change and disaster management policies

Six national policies elucidate the context of $\mathrm{NbS}$ in natural disasters management and climate change response (Figure2).

\section{Bangladesh Climate Change Strategy and Action Plan (2009)}

The Bangladesh Climate Change Strategy and Action Plan (BCCSAP) was published in 2008 and further revised in 2009. This document included programs related to natural resources, such as land and water resources to ensure food security, disaster management, mitigation of greenhouse gas emissions, and low-carbon development. However, the plan did not outline detailed activities to implement these programs. It also included programs concerning research and knowledge management to comprehend the impacts of climate change on ecosystems and biodiversity (MoEF 2009a). Priority was given to expanding social forestry and coastal "greenbelt" afforestation programs to reduce greenhouse gas emissions. The government is in the process of revising the Action Plan and may address
$\mathrm{NbS}$ in the updated version, although elements of the concept are already present in the current plan.

National Adaptation Programme of Action (2009)

The National Adaptation Programme of Action (NAPA) was adopted by the Government of Bangladesh in 2005 and further updated in 2009. The updated version of NAPA incorporated findings from previous studies to deal with the adverse impacts of climate change. It also extended adaptation system measures from immediate and emergency to medium- and long-term. It emphasized four security issues of Bangladesh: food; energy; water; and livelihood security. NAPA highlighted the importance of water ecosystems, forest, and biodiversity measurement to monitor and research the impact of climate change (MoEF 2009b). It also mentioned strengthening community-based adaptation programs, such as afforestation programs, and deploying them in every disaster-prone part of the country as a potential adaptation system for disaster management (MoEF 2009b). However, it did not mention the term $\mathrm{NbS}$ or any of the related concepts, such as ecosystem services or EbA, that can address the impacts of climate change in the country.

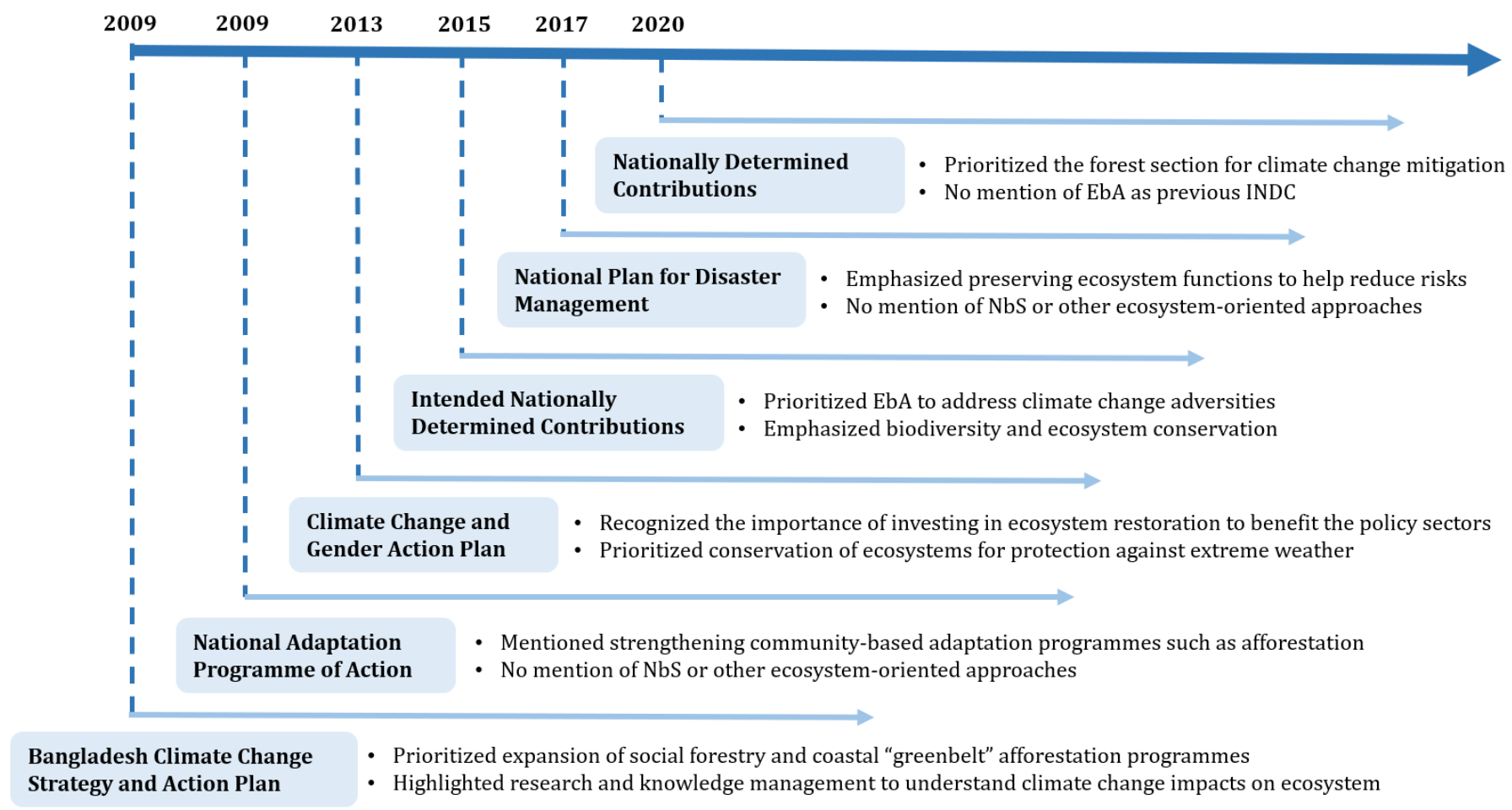

Figure 2: Timeline of climate change and disaster management policies 


\section{Climate Change and Gender Action Plan (2013)}

The Bangladesh Climate Change and Gender Action Plan (ccGAP) was developed in 2013 to promote gender equality in climate change policies and strategies. The document recognized the impacts of climate change on marine and freshwater ecosystems, which in turn directly impacts employment opportunities (MoEF 2013). Investment in natural capital and conservation of ecosystems to avoid crises and catastrophes or to mitigate their consequences was also prioritized (MoEF 2013). While ccGAP does not mention any $\mathrm{NbS}$ terminologies in the document, it did emphasize natural ecosystem conservation.

Intended Nationally Determined Contributions (2015) The Ministry of Environment and Forests published the Bangladesh Intended Nationally Determined Contributions (INDC) in 2015. The document identified a number of areas to address the adverse effects of climate change, including biodiversity, ecosystem conservation, and EbA (MoEF 2015). The document also provided an estimated cost of $\$ 2.5$ million USD for EbA (MoEF 2015). NbS terminology was absent in the document, although EbA and ecosystem conservation falls under the $\mathrm{NbS}$ umbrella (Cohen-Shacham, et al. 2016).

The National Plan for Disaster Management (2017)

The National Plan for Disaster Management (NPDM) 2016-2020 was developed by the Ministry of Disaster Management and Relief in 2017 after the Plan of 2010-2015. The document focused on addressing the emerging risks of urbanization and climate change, and placed importance on disaster risk reduction. The Plan emphasized preserving ecosystems, though there was no mention of NbS (MoDMR 2017).

\section{Nationally Determined Contributions (2020)}

The Ministry of Environment, Forest and Climate Change submitted the interim Nationally Determined Contributions (NDC) of Bangladesh in 2020. The forest sector was prioritized for climate change adaptation, where initiatives included increasing forest cover, reducing forest degradation and deforestation, and implementing social forestry (MoEFCC 2020). However, whereas EbA was explicitly prioritized in the INDC 2015, neither EbA nor NbS were directly mentioned in the interim NDC.

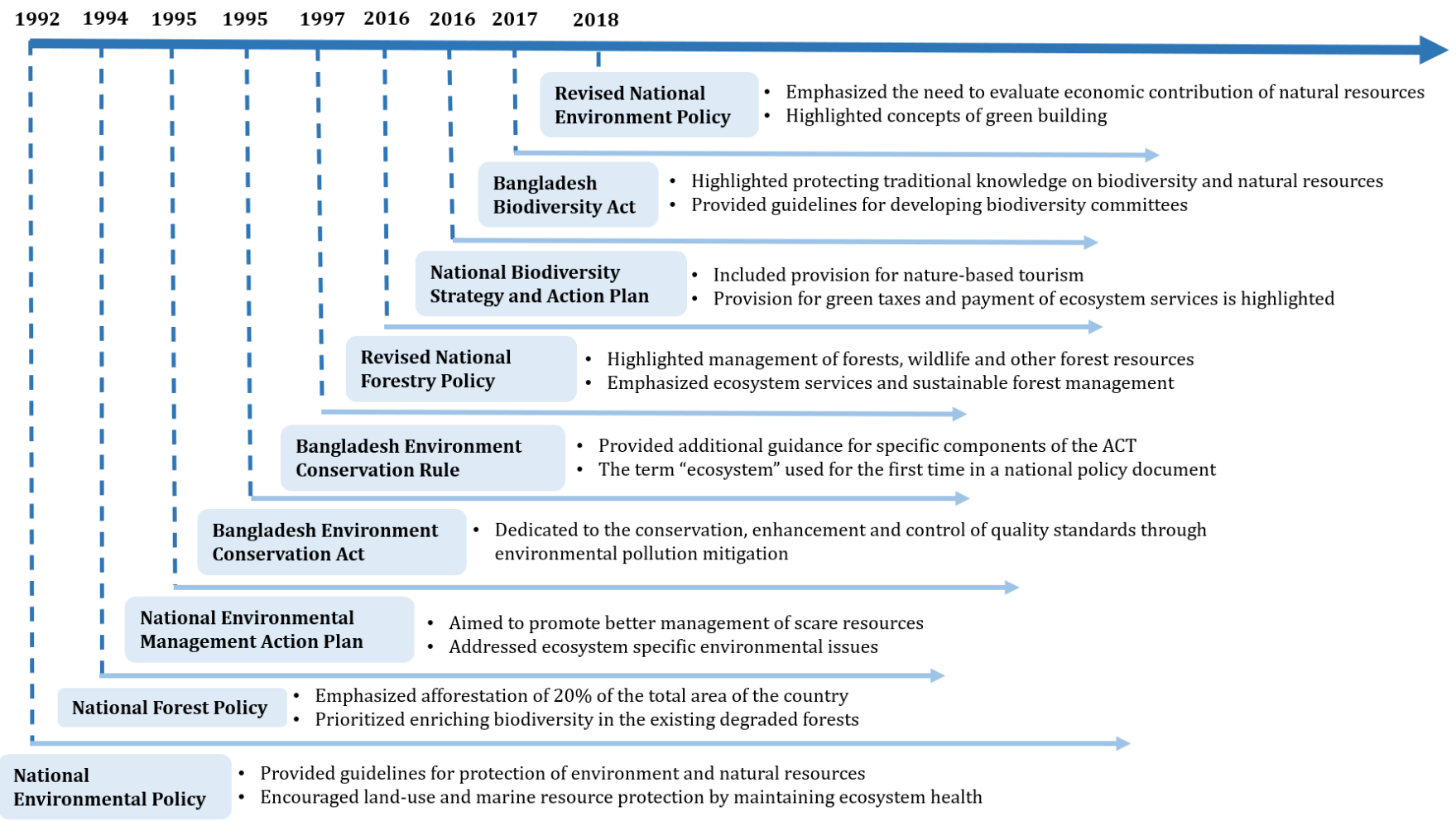

Figure 3: Timeline of national environment and forest policies 
iii. NbS in environment and forest policies

Nine national policies, acts, and rules contextualizing $\mathrm{NbS}$ relate to environment and forests (Figure3).

National Environmental Policy (1992)

The main theme of the National Environmental Policy (NEP), enacted in 1992, was to maintain ecological balance and overall development through environmental protection and improvement. It provided multiple guidelines to protect the environment and natural resources across fifteen sectors (including agriculture, industry, health, energy, water development, flood control and irrigation, land, forest, wildlife and biodiversity, fisheries and livestock, food, and coastal and marine environment). Although the policy did not include the concept of $\mathrm{NbS}$, it encouraged land-use and marine resource protection by developing and maintaining ecosystem health. It also considered environmental impacts while planning urbanization and housing (MoEF 1992).

\section{National Forest Policy (1994)}

The National Forest Policy (NFP) was enacted in 1994 to initiate a twenty-year Forestry Master Plan. The main objectives of this policy were to: afforest about $20 \%$ of the country; enrich biodiversity in the existing degraded forests; and fulfill national responsibilities and commitments relating to global warming ( $\mathrm{GoB}$ 1994). As of 2019, the forest cover of Bangladesh is about $17 \%$ of the total land area of the country (Reza and Hasan 2019). While NbS was not introduced at that point, the policy highlighted afforestation and enriching biodiversity, which can be considered as components of $\mathrm{NbS}$.

\section{National Environmental Management Action Plan} (1995)

The National Environmental Management Action Plan (NEMAP) promoted better management of scarce resources to reverse current trends in environmental degradation, and also to raise awareness of the environment (MoEF 1995a). These interventions aligned with the objectives of $\mathrm{NbS}$ to sustainably manage natural resources. The plan developed a forecasting mechanism for disasters, community awareness, and disaster management plans to reduce the impact of natural hazards (MoEF 1995a).
Bangladesh Environment Conservation Act (1995) and Rule (1997)

The Bangladesh Environmental Conservation Act (ECA) was passed in 1995 and accompanied by the 1997 Rules. The Act was dedicated to the conservation and enhancement of environmental conditions. It provided guidelines to ensure quality standards for the environment by reducing pollution from the various environmental polluting industries and sectors (MoEF 1995b). Moreover, the Environment Conservation Rules adopted in accordance with the 1995 Act provided additional guidance for specific components of the Act (Clemett 2006). The term "ecosystem" was defined in this policy document (MoEF 1995b).

\section{Revised National Forestry Policy (2016)}

In 2016, Bangladesh updated the National Forest Policy (1994). The objective was to manage all existing forests, wildlife, and other forest resources to build sustainable management and climate resilience, enrich degraded forest areas, and produce a wide range of goods and services for the ecosystem (MoEF 2016a). The policy planned to cover at least $20 \%$ of the country with trees by 2035 to enrich forest areas. It also enhanced ecosystem services and sustainable forest management in order to address the effects of climate change on forest ecosystems (MoEF 2016a). Thus, the policy includes several (forest ecosystembased) components of $\mathrm{NbS}$.

National Biodiversity Strategy and Action Plan of Bangladesh (2016)

The National Biodiversity Strategy and Action Plan (NBSAP) implemented the three objectives of the international Convention on Biological Diversity (CBD): conservation of biodiversity; sustainable use of natural resources; and fair and equitable sharing of the benefits arising from the utilization of genetic resources. This document included provisions for nature-based tourism as well. Furthermore, it evaluated ecosystem goods and services to integrate into national accounting. Additionally, it included policies for green taxes, payment for ecosystem services, and fines for polluters to protect biodiversity and control pollution (MoEF 2016b).

\section{Bangladesh Biodiversity Act (2017)}

Bangladesh is one of the state members of the CBD, and to protect the global and national commitment to biodiversity conservation and implement the NBSAP, 
the Ministry of Environment, Forest and Climate Change adopted the Bangladesh Biodiversity Act (BBA) in 2017. It provided clear directives for increasing biodiversity and protecting endangered species. This document further aimed to protect traditional knowledge of biodiversity and natural resources. In addition, it provided guidelines for developing biodiversity committees at the national to local levels (MoEFCC 2017). Even though the Act did not provide directives for $\mathrm{NbS}$, it emphasized the protection and management of natural resources and biodiversity.

\section{Revised National Environment Policy (2018)}

The National Environment Policy was adopted in 2018 to protect the environment, control pollution, and conserve biodiversity from the negative impacts of climate change (MoEF 2018). It emphasized evaluating the economic contribution of natural resources and highlighted multiple vital strategies, like polluter fines, payment for ecosystem services, and emission taxes (MoEF 2018). It also stressed the need to ensure equitable accessibility to ecosystem services by local people (MoEF 2018). In addition, this policy highlighted components of $\mathrm{NbS}$, such as green- and eco-building and energy efficient construction for future urbanization (MoEF 2018).

\section{Findings and discussion}

\section{i. Distinguishing Nbs concepts in the existing policies of Bangladesh.}

Bangladesh's EFCC CIP, ccGAP, INDC, and NBSAP frequently mentioned EbA in the policy documents. EbA primarily focuses on climate change adaptation and has a more limited scope than $\mathrm{NbS}$, although it is a component of $\mathrm{NbS}$ (Pauleit, et al. 2017). According to Seddon et al. (2020), NbS has the potential to tackle both climate adaptation and mitigation challenges at low cost while delivering multiple additional benefits for people and nature. For example, restoring natural forests in upper catchments can protect communities downstream from flooding, increase carbon sequestration, and protect biodiversity (Seddon, et al. 2020). Thus, EbA focuses on participatory community-based adaptation strategies by emphasizing sustainable management, conservation, and restoration of ecosystems. In contrast, $\mathrm{NbS}$ differ from traditional biodiversity conservation and management approaches by specifically aiming to address broad societal goals such as human well-being, poverty allevietion, and socio-economic development (Seddon, et al. 2020). An example of NbS is planting trees and increasing green spaces in cities to help with urban cooling and flood abatement while also storing carbon, mitigating air pollution, and providing health benefits (Seddon, et al. 2020).

More recently published policies have started to explore the concept of green infrastructure. This particular approach falls under the NbS umbrella (Cohen-Shacham, et al. 2019; Eggermont, et al. 2015). Green infrastructure is a planning approach which can provide strategic guidance for integrating $\mathrm{NbS}$ in developing green spaces at various scales (Pauleit, et al. 2017). However, the limited appearance of green infrastructure in the policies may indicate a lack of understanding of the concept, which is at the heart of NbS. (Jato-Espino, Sañudo-Fontaneda and AndrésValeri 2018).

We also investigated the concept of ecosystem services. This term is more frequently used than the other ecological approaches (i.e. EbA and green infrastructure) mentioned in the policies, and refers to benefits people obtain from ecosystems (Pauleit, et al. 2017). Ecosystem services are often valued for providing immediate benefits to human well-being and economy, while $\mathrm{NbS}$ emphasizes benefits to people and the environment itself, which allows for sustainable solutions that are able to respond to environmental change and hazards in the long term (Eggermont, et al. 2015).

Across the policies, disaster management is a major concern, especially in the national development policies and climate change policies. However, in most policies, creating coastal green belts or coastal afforestation is the only initiative presented for disaster management. There are other NbS initiatives that can be tapped for disaster management. For example, green roofs can reduce stormwater runoff by promoting rainfall infiltration on the tops of buildings, and open spaces such as parks and greenways can capture runoff from upstream basins and adjacent areas (World Bank 2018). By mainstreaming $\mathrm{NbS}$ in national policy and planning, these multiple benefits of $\mathrm{NbS}$ can be exploited for managing and reducing disasters in urban, freshwater, and coastal areas. 
$\mathrm{NbS}$ are also meant to engage and integrate indigenous peoples and local communities (Seddon, et al. 2021). In PP 2021-2041, the policy emphasized increasing forest coverage in hilly regions without considering the impact on the ethnic communities there. Through the integration of $\mathrm{NbS}$, these issues might be addressed by policies in a more structured and inclusive manner. Moreover, most of the approaches to address the adverse effects of climate change are engineered interventions; in Bangladesh, 291 out of 329 (88\%) adaptation projects approved by the Bangladesh Climate Change Trust between 2009 and 2016 involved engineered interventions, while only thirty-eight involved NbS (Seddon, et al. 2020). Although NbS concepts and related terminology have entered the policy discourse of Bangladesh, systematic uptake of the approaches has been lacking. NbS can function as a framework for these approaches and ensure systematic integration into the policies and further effective implementation.

\section{ii. Prevalence of NbS-related terminology and concepts in the policy discourse}

The results of the policy review suggest that, throughout the past three decades, several policies in Bangladesh emphasized ecosystem-oriented approaches, such as EbA, green or eco-building, enhancing biodiversity, and conservation of natural resources (Figure4 and Table A1). The policy documents also emphasized disaster management. However, these concepts have remained disconnected; none of these documents applied EbA or ecosystem services as a potential tool for disaster management. Additionally, among the twenty policies, nineteen of the policies did not explicitly mention or use the term NbS to address societal challenges and climate change in the country; the recent 8FYP was the first policy document to do so, suggesting an emerging awareness of the terminology in the policy discourse (Table A1).

Across the national development policies, the recent documents incorporate ecosystem conservation and improvement, along with emphasizing the importance of $\mathrm{EbA}$ and green infrastructure. Bangladesh EFCC CIP (2016-2021) used "EbA" the most among these policies, while BDP 2100 and 7FYP prioritized "ecosystem" conservation and "disaster management," respectively. The use of these terms is also prevalent in the national climate change and disaster management policies. EbA was prioritized across two documents (ccGAP and INDC)-these policies mostly focused on conservation of existing ecosystems rather than on restoration.

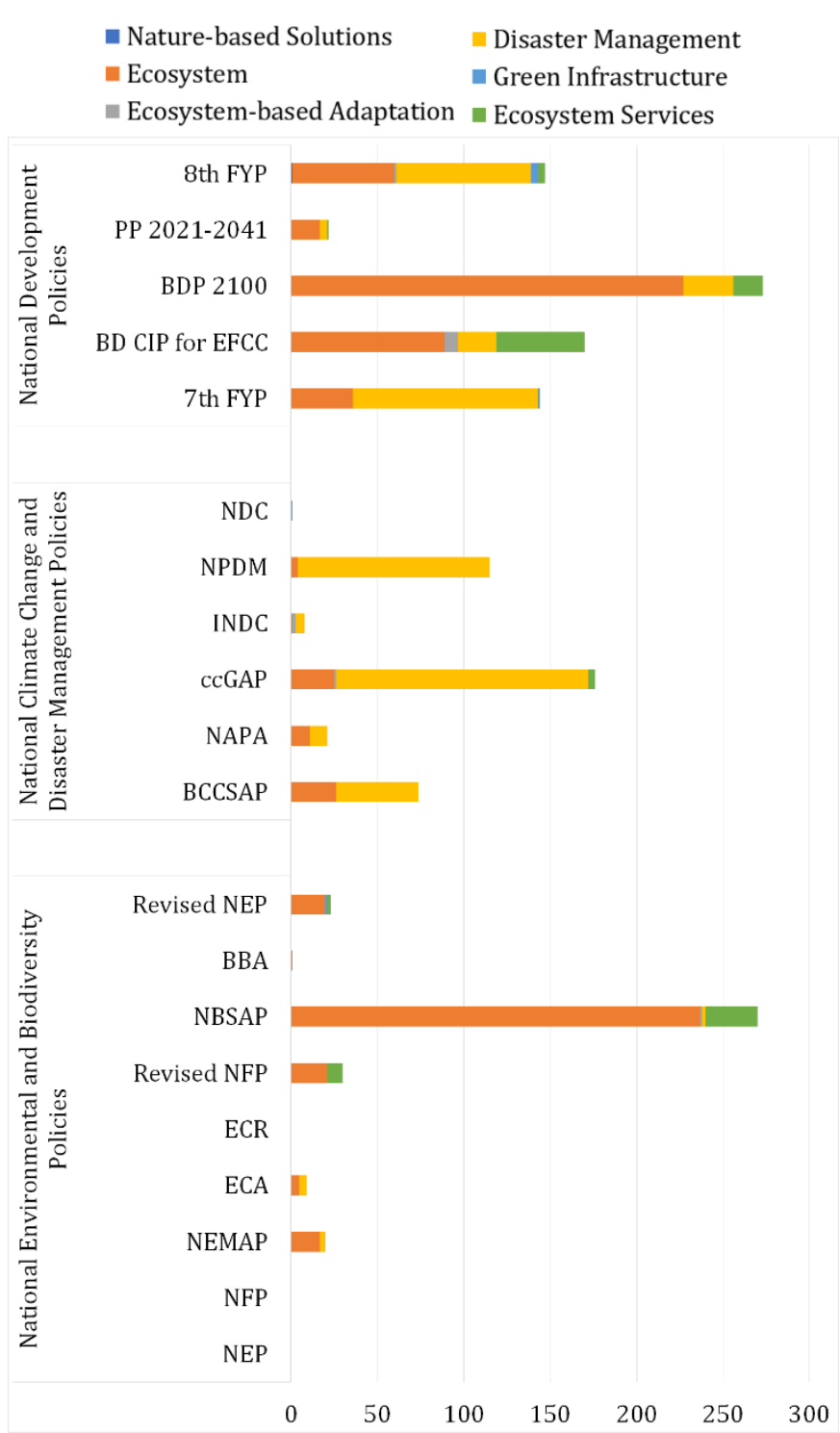

Figure 4: Frequency of nature and ecosystem-oriented keywords in the national policies (arranged in reverse chronological order per sector)

The environment and forest policies focused on the protection, management, and conservation of natural resources and ecosystems, with recent policies tilting more towards the enrichment of ecosystems as well as equitable access and finance of ecosystems.

The term "NbS" appeared in the 8FYP, as it stated that the upcoming NAP would prioritize NbS. However, although $\mathrm{NbS}$ appeared for the first time in a Bangladeshi policy document, the plan includes 
neither any explanation of the term nor any national guidelines or strategies. It is important that the term is being understood properly to facilitate effective strategies and implementation. Nonetheless, the use of the term in the 8FYP and its prioritization in the NAP can be considered as the first step for mainstreaming NbS.

Among the other policies, none used or applied the term "NbS" to address societal challenges or climate change in Bangladesh; nevertheless, several policies (7FYP, EFCC CIP, and PP 2021-2041) highlighted the importance of conservation, protection, and management of forest ecosystems, resources, and fisheries. Protection, conservation, and management of these ecosystems fall under $\mathrm{NbS}$ according to Eggermont et al. (2015). NbS also incorporates the creation of new ecosystems, such as green roofs (Eggermont, et al. 2015). Furthermore, according to the International Union for Conservation of Nature (IUCN) definition of $\mathrm{NbS}$, the concept can be regarded as a tool for addressing societal challenges, such as mitigating climate change and providing socioeconomic benefits (IUCN 2020). Integrating NbS in policies, not just its umbrella-enveloped concepts addressing environmental conservation, may have the benefit of addressing social and economic challenges more extensively than simple conservation measures.

iii. Global commitments and upcoming policies in Bangladesh that include NbS

$\mathrm{NbS}$ is gaining rapid attention in global climate change discussions. For instance, the United Nations (UN) Climate Action Summit of 2019 included NbS as one of its main tracks; the $25^{\text {th }}$ Conference of the Parties to the UN Framework Convention on Climate Change discussed NbS, and China and New Zealand created a "Nature-based Solution Coalition." To align and keep up with global knowledge and trends, it is important that policymakers recognize NbS concepts at the national level to realize its potential.

The people and government of Bangladesh have appreciated nature-based actions, which is evident in the policy documents such as BDP 2100, 7FYP, INDC, and BCCSAP. Additionally, the 8FYP prioritized NbS in the NAP of Bangladesh. As an emerging term, policymakers and stakeholders can continue discussing $\mathrm{NbS}$ to carry out effective implementation and inclusion of this framework for climate change adaptation and mitigation in the national policy discourses.

\section{iv. Lack of financial provisions for $\mathrm{NbS}$}

Funding for ecosystem and NbS-related actions infrequently occur in the selected national policies. For instance, some policies proposed green taxes and payments for ecosystem services. However, potential investors and donors, financing, and allocation strategies for the ecosystem-oriented approaches are not outlined in these policies. Thus, government investments on these approaches are scattered, and relevant funding is mostly integrated into development or climate change budgets. Subsequently, monitoring and evaluation of how much of these finances flow to $\mathrm{NbS}$ and related concepts is difficult to quantify.

There are funding mechanisms for climate change adaptation issues, such as Adaptation Fund, Green Climate Fund, and Bangladesh Climate Change Resilience Fund. Depending on project objectives, the government can acquire financial support through these funds to carry out NbS-related projects. However, to monitor and evaluate financing towards $\mathrm{NbS}$, it is important to establish robust financing mechanisms and reporting systems for NbS-related projects.

v. Realizing the limitations of $\mathrm{NbS}$ and this analysis While promoting the integration of $\mathrm{NbS}$ in national policy documents, we need to acknowledge that $\mathrm{NbS}$ also entail challenges and limitations. In terms of participation and equity, there is a lack of public understanding of $\mathrm{NbS}$, and the social and cultural elements important for promoting sustainable development (Nelson, et al. 2020). Furthermore, the potential of $\mathrm{NbS}$ in providing intended benefits has not been rigorously assessed. The cost-effectiveness of $\mathrm{NbS}$ interventions compared to engineered alternatives are also not clear (Seddon, et al. 2020). In addition to evaluating the efficacy of natural solutions for climate change, we need to conduct further research assessing the feasibility and long-term responses of $\mathrm{NbS}$ to global warming and sea level rise (Molino, Kenney and Sutton-Grier 2020). There are possibilities of trade-offs arising from climate mitigation policies if they encourage $\mathrm{NbS}$ with low biodiversity value, such as afforestation with nonnative monocultures. This can result in maladaptation, especially in a rapidly changing world 
where biodiversity-based resilience and multifunctional landscapes are key (Seddon, et al. 2020). Moreover, at the governance level, even though there is increasing political will at various scales (local, national, regional, and global), governments may lack the commitment to implement various nature-based initiatives (Nelson, et al. 2020). Hence, the term "solutions" allow NbS to promote the idea of quick and tidy outcomes, but these solutions require ongoing evaluation to learn from past decisions. Thus, realizing the potential of $\mathrm{NbS}$ depends on effective consultation with the public and policymakers, and addressing not just the possible benefits, but also the tough road to get there (Nelson, et al. 2020).

Finally, this study analyzed twenty policies to assess the national policy landscape in the context of using to address societal challenges in Bangladesh. While verifying the outputs and practical applications of past policies and plans was beyond the scope of this study, future research can consider primary data collection and stakeholder consultations to investigate the impacts, progress, and outcomes of $\mathrm{NbS}$ policies. Moreover, we studied only recent national development policies and climate change and disaster management policies, as the older policies in these sectors generally did not consider ecosystem and nature-oriented concerns; the inclusion of these approaches is relatively recent in these sectors. However, the environment and forest policies have considered nature and ecosystems for decades, so we considered older policies in these sectors.

\section{Policy recommendations}

Realizing the full potential of $\mathrm{NbS}$ requires that national policies rigorously address components focused on climate change adaptation and mitigation. As discussed in Section IV, there are various entry points to integrate $\mathrm{NbS}$ and contribute to future sustainable approaches for climate change adaptation in Bangladesh. Based on the analysis, the following issues should be addressed to integrate the holistic indicators of $\mathrm{NbS}$ at the national policy level:

i. Adopt NbS across national development, climate change, environmental, and forestry policies: Several national policies have already prioritized natural ecosystems and their conservation in development, climate change, and disaster risk reduction strategies, along with the latest policy document mentioning $\mathrm{NbS}$ for the first time. Thus, NbS and its components can be adopted among these national development policies to ensure the future sustainable development for nature, as well as human well-being, in Bangladesh.

ii. Strengthen inter-ministerial and inter-departmental coordination and cooperation to promote NbS: The government needs to ensure coordination amongst various sectors to ensure a sustainable future. As NbS is an umbrella concept emphasizing multiple sectors (water, disaster, land, soil, infrastructure, etc.), stronger coordination across these various sectors, from the local to national level, is vital to implement $\mathrm{NbS}$.

iii. Provide funding for $\mathrm{NbS}$ in national policies: Finance is a vital issue in implementing various interventions of NbS. Bangladesh EFCC CIP and NBSAP highlight several funding mechanisms for environment, forest, and climate change programs. Future policies can develop specific guidelines for funding and investment of $\mathrm{NbS}$. For example, encouraging private-public partnership for financing nature-based interventions, requiring naturefriendly taxes, reducing fees on $\mathrm{NbS}$ interventions, or employing incentive schemes or compensation mechanisms can help fund $\mathrm{NbS}$ initiatives. Additionally, international funding can be tapped through global climate change negotiation to promote $\mathrm{NbS}$ as an effective adaptation strategy. Proper measurement, reporting, and verification systems can also ensure sustainable finance mechanisms to benefit from $\mathrm{NbS}$.

iv. Strengthen monitoring and evaluation mechanism of national policies on NbS: As mentioned in Section $\mathrm{IV}$, the cost-effectiveness of $\mathrm{NbS}$ interventions compared to engineered alternatives and their resilience to climate change are still not clear (Seddon, et al. 2020). Thus, it is highly important to formulate specific indicators and mechanisms for monitoring and evaluating $\mathrm{NbS}$, and integrate these across various policies to evaluate the efficacy of $\mathrm{NbS}$.

v. Develop a national platform for $\mathrm{NbS}$ with concerned stakeholders: A national platform for $\mathrm{NbS}$ can provide common knowledge to share with multiple stakeholders, including policymakers, local communities, experts, and other concerned parties to 
discuss various challenges and strategies for proper implementation of $\mathrm{NbS}$. This platform can achieve policy advocacy, research and knowledge management, and capacity building of the concerned stakeholders. A web portal can also be developed to gather available data and information around the $\mathrm{NbS}$ interventions in Bangladesh. Hence, this platform can function as a knowledge bridge between policymakers, practitioners, and local community members, as well as to enhance knowledge on $\mathrm{NbS}$.

vi. Ensure inclusive participation of women, youth, and marginalized people as vital actors of $\mathrm{NbS}$ implementation: $\mathrm{NbS}$ seeks to ensure that policies are inclusive and participatory. As women, youth, and other marginalized groups are often highly vulnerable to climatic threats, they should be considered as important agents for implementing $\mathrm{NbS}$ policies. The Bangladesh Biodiversity Act (2017) and National Environment Policy (2018) highlighted the need to ensure the equitable accessibility of the variety of ecosystem services by local people. Therefore, national policies and plans should include the involvement of marginalized communities, youth, and women to facilitate equitable implementation of NbS practices.

\section{Conclusion}

Bangladesh is extremely vulnerable to climate change, and the government has already acknowledged the need to adapt to the changing climate at the national policy level. While the country is rapidly developing and prioritizing adaptation strategies by focusing on infrastructure, it needs to acknowledge the role nature plays in its economy, disaster risk reduction, and climate change adaptations. Ecosystem and nature-oriented approaches have long been practiced in the country, however, the terminology of NbS has only recently attained momentum.

Our findings suggest that earlier national policy documents emphasize protection, conservation, and management of the country's natural ecosystems and included several relevant actions that fall under the umbrella of NbS. However, these concepts and approaches have limitations that $\mathrm{NbS}$ can help overcome, which can also address sustainable development, human well-being, and biodiversity. The term was used in the recently published 8FYP, which indicates that the policy sphere of Bangladesh is ready to take on and explore the potential of the concept. Therefore, $\mathrm{NbS}$ can be applied as a potential mechanism in upcoming policies in a more structured and inclusive manner to address climate change adaptation and disaster management.

While promoting NbS across the policy discourse in addressing climate change and socio-economic challenges, we must recognize that the concept is still new and consider challenges and limitation of $\mathrm{NbS}$ to avoid maladaptation. In light of limitations, consultation with relevant stakeholders, facilitation of inter-ministry coordination, development of national funding and monitoring mechanisms, and pursuit of evidence-based research can enhance effective implementation of $\mathrm{NbS}$ in the country. Finally, inclusion of local knowledge and involvement of youth, marginalized people, and women can ensure transparent governance and foster Bangladesh's resilience against climate change. 
Appendix: Occurrence of terminologies related to NbS in policy documents of Bangladesh 1992 to 2020

\begin{tabular}{|c|c|c|c|c|c|c|c|c|}
\hline & Policy & Year & $\mathrm{NbS}$ & ES & $\mathrm{EbA}$ & DM & GI & ESS \\
\hline \multicolumn{9}{|c|}{ National Development Policies } \\
\hline 1. & Seventh Five Year Plan & 2015 & 0 & 36 & 0 & 107 & 1 & 0 \\
\hline 2. & $\begin{array}{l}\text { Bangladesh Country Investment Plan for Environment, } \\
\text { Forest and Climate Change }\end{array}$ & 2017 & 0 & 89 & 8 & 22 & 0 & 51 \\
\hline 3. & Bangladesh Delta Plan 2100 & 2018 & 0 & 227 & 0 & 29 & 0 & 17 \\
\hline 4. & Perspective Plan 2021-2041 & 2020 & 0 & 17 & 0 & 4 & 0 & 1 \\
\hline 5. & Eighth Five Year Plan & 2020 & 1 & 59 & 1 & 78 & 4 & 4 \\
\hline \multicolumn{9}{|c|}{ National Climate Change and Disaster Management Policies } \\
\hline 6. & Bangladesh Climate Change Strategy and Action Plan & 2009 & 0 & 26 & 0 & 48 & 0 & 0 \\
\hline 7. & National Adaptation Programme of Action & 2009 & 0 & 11 & 0 & 10 & 0 & 0 \\
\hline 8. & Climate Change and Gender Action Plan & 2013 & 0 & 25 & 1 & 146 & 0 & 4 \\
\hline 9. & Intended Nationally Determined Contributions & 2015 & 0 & 1 & 2 & 5 & 0 & 0 \\
\hline 10. & National Plan for Disaster Management & 2017 & 0 & 4 & 0 & 111 & 0 & 0 \\
\hline 11. & Nationally Determined Contributions & 2020 & 0 & 0 & 0 & 0 & 1 & 0 \\
\hline \multicolumn{9}{|c|}{ National Environment and Biodiversity Policies } \\
\hline 12. & National Environmental Policy & 1992 & 0 & 0 & 0 & 0 & 0 & 0 \\
\hline 13. & National Forest Policy & 1994 & 0 & 0 & 0 & 0 & 0 & 0 \\
\hline 14. & National Environmental Management Action Plan & 1995 & 0 & 17 & 0 & 3 & 0 & 0 \\
\hline 15. & Environment Conservation Act & 1995 & 0 & 5 & 0 & 4 & 0 & 0 \\
\hline 16. & Environment Conservation Rule & 1997 & 0 & 0 & 0 & 0 & 0 & 0 \\
\hline 17. & Revised National Forestry Policy & 2016 & 0 & 21 & 0 & 0 & 0 & 9 \\
\hline 18. & National Biodiversity Strategy and Action Plan of Bangladesh & 2016 & 0 & 237 & 1 & 2 & 0 & 30 \\
\hline 19. & Bangladesh Biodiversity Act & 2017 & 0 & 1 & 0 & 0 & 0 & 0 \\
\hline \multirow[t]{2}{*}{20.} & Revised National Environment Policy & 2018 & 0 & 20 & 0 & 0 & 1 & 2 \\
\hline & Recurrence of terminologies highlighted in the policies & & 1 & 796 & 13 & 569 & 7 & 118 \\
\hline
\end{tabular}

Table A1: Tabulated occurrence of terminologies related to $\mathrm{NbS}$ in policy documents of Bangladesh from ${ }^{1}$

${ }^{1}$ Nature-based Solutions (NbS); Ecosystem (ES); Ecosystem-based Adaptation (EbA); Disaster Management (DM); Green Infrastructure (GI); Ecosystem Services (ESS). The bottom row (in grey) represents the total uses of terminologies highlighted in the policies. 


\section{References}

Alam, Shamsul. 2019. Bangladesh development perspectives: Planning strategies. The Financial Express.

https://thefinancialexpress.com.bd/public/views/ba ngladesh-development-perspectives-planningstrategies-1575038474

Alam, Khorshed, and Md. Abu Taiyeb Chowdhury. 2018. "Floating Vegetable Gardening (FVG) as a Sustainable Agricultural System in Bangladesh: Prospects for Kaptai Lake, Rangamati, Chittagong Hill-Tracts." OIDA International Journal of Sustainable Development 4358. https://ssrn.com/abstract=3251130

Almenar, Javier Babí, Thomas Elliot, Benedetto Rugani, Bodénan Philippe, Tomas Navarrete Gutierrez, Guido Sonnemann, and Davide Geneletti. 2021. "Nexus between nature-based solutions, ecosystem services and urban challenges." Elsevier.

https://doi.org/10.1016/j.landusepol.2020.104898

Augusto, Bruno, Peter Roebeling, Sandra Rafael, Joana Ferreira, Ana Ascenso, and Carole Bodilis. 2020. "Short and medium- to long-term impacts of naturebased solutions on urban heat." Sustainable Cities and Society. https://doi.org/10.1016/j.scs.2020.102122

Badola, Ruchi, and S.A. Hussain. 2005. "Valuing ecosystem functions: an empirical study on the storm protection function of Bhitarkanika mangrove ecosystem, India." Cambridge University Press 85-92.

https://doi.org/10.1017/S0376892905001967

Bhattacharjee, Atasi. 2021. "Energy efficiency and green building pathways." New Age. https://www.newagebd.net/print/article/130872

Carro, Inti, Leonardo Seijo, Gustavo J. Nagy, Ximena Lagos, and Ofelia Gutierrez. 2018. "Building capacity on ecosystem-based adaptation strategy to cope with extreme events and sea-level rise on the Uruguayan coast." International Journal of Climate Change Strategies and Management 504-522. https://doi.org/10.1108/IJCCSM-07-2017-0149

Clemett, Alexandra. 2006. A review of environmental policy and legislation in Bangladesh. Department of International Development.

Cohen-Shacham, E., C. Janzen., Stewart Maginnis, and Gretchen Walters. 2016. Nature-based solutions to address global societal challenges. Gland, Switzerland: IUCN. https://doi.org/10.2305/IUCN.CH.2016.13.en

Cohen-Shacham, Emmanuelle, Angela Andrade, James Dalton, Nigel Dudley, Mike Jones, Chetan Kumar, Stewart Maginnis, et al. 2019. "Core principles for successfully implementing and upscaling Naturebased Solutions." Environmental Science \& Policy 2029. https://doi.org/10.1016/j.envsci.2019.04.014
Eckstein, David, Vera Künzel, Laura Schäfer, and Maik Winges. 2019. GLOBAL CLIMATE RISK INDEX 2020. Germanwatch e.V.

Eggermont, H., E. Balian, J.M.N. Azevedo, V. Beumer, T. Brodin, J. Claudet, B. Fady, et al. 2015. "Nature-based solutions: new influence for environmental management and research in Europe." GAIA Ecological Perspectives for Science and Society 243248. https://doi.org/10.14512/gaia.24.4.9

European Commission. 2015. Towards an EU research and innovation policy agenda for naturebased solutions \& re-naturing cities. Final Report of the Horizon 2020 Expert Group on Nature-Based Solutions and ReNaturing Cities. https://doi.org/10.2777/479582

GED. 2018. Bangladesh Delta Plan 2100. Dhaka: General Economics Division, Government of the People's Republic of Bangladesh.

GED. 2020b. Eighth Five Year Plan. Dhaka: General Economics Division, Government of the People's Republic of Bangladesh.

GED. 2020a. Perspective Plan of Bangladesh 2021-2041. Dhaka: General Economics Division, Ministry of Planning, Government of the People's Republic of Bangladesh.

GED. 2015. Seventh Five Year Plan FY 2016-FY2020. Dhaka: General Economic Division, Ministry of Planning, Government of the People's Republic of Bangladesh.

GoB. 1994. National Forest Policy. Government of the People's Republic of Bangladesh.

IFRC Report. 2020. Final Report Bangladesh: Cyclone Bulbul. International Fedaration of Red Cross and Red Cresent Society.

Irfanullah, Hasib Md., Md.A.K. Azad, A.K.M. Kamruzzaman Khan, and Md. Ahsanul Wahed. 2011. "Floating gardening in Bangladesh: a means to rebuild lives after devastating flood." Indian Journal of Traditional Knowledge 31-38.

Islam, Md. Tarikul, and Melissa Nursey-Bray. 2017. "Adaptation to climate change in agriculture in Bangladesh: The role of formal institutions." Journal of Environmental Management 347-358.

https://doi.org/10.1016/j.jenvman.2017.05.092

IUCN. 2020. Guidance for using the IUCN Global Standard for Nature-based Solutions. Gland, Switzerland: IUCN. https://doi.org/10.2305/IUCN.CH.2020.09.en

Jato-Espino, Daniel, Luis Angel Sañudo-Fontaneda, and Valerio C. Andrés-Valeri. 2018. "Green Infrastructure: Cost-Effective Nature-Based Solutions for Safeguarding the Environment and Protecting Human Health and Well-Being." In Handbook of

Environmental Materials Management, 1-27. Springer International Publishing. https://doi.org/10.1007/978-3-319-58538-3 46-1

Kibria, Golam. 2014. "Mangrove forests-its role in livelihoods, carbon sinks and disaster mitigation." https://doi.org/10.13140/RG.2.1.1848.8800 
MoDMR. 2017. National Plan for Disaster Management. Dhaka: Ministry of Disaster Management and Relief, Government of the People's Republic of Bangladesh.

MoEF. 2013. Bangladesh Climate Change and Gender Action Plan. Dhaka: Ministry of Environment and Forests, Government of the People's Republic of Bangladesh.

MoEF. 2009a. Bangladesh Climate Change Strategy and Action Plan. Dhaka: Ministry of Environment and Forests, Government of the People's Republic of Bangladesh.

MoEF. 2017. Bangladesh Country Investment Plan for Environment, Forestry and Climate Change. Dhaka: Ministry of Environment and Forests, Government of the People's Republic of Bangladesh.

MoEF. 1995b. Bangladesh Environment Conservation Act. Ministry of Environment and Forests, Government of the People's Republic of Bangladesh.

MoEF. 2015. Intended Nationally Determined Contributions. Dhaka: Ministry of Environment and Forests, Government of the People's Republic of Bangladesh.

MoEF. 2009b. National Adaptation Programme of Action. Dhaka: Ministry of Environment and Forests, Government of the People's Republic of Bangladesh.

MoEF. 1995a. National Environmental Management Action Plan. Dhaka: Ministry of Environment anf Forests, Government of the People's Republic of Bangladesh.

MoEF. 2018. National Environment Policy. Dhaka: Ministry of Environment, Forest and Climate Change, Government of the People's Republic of Bangladesh.

MoEF. 2016a. National Forestry Policy. Dhaka: Ministry of Environment and Forests, Government of the People's Republic of Bangladesh.

MoEF. 1992. The Environmental Policy 1992. Dhaka: Ministry of Environment and Forests, Government of the People's Republic of Bangladesh.

MoEF. 2016b. National Biodiversity Strategy and Action Plan of Bangladesh. Ministry of Environment and Forests, Government of the People's Republic of Bangladesh.

MoEFCC. 2017. Bangladesh National Biodiversity Act. Dhaka: Ministry of Environment and Forests, Government of the People's Republic of Bangladesh.

MoEFCC. 2020. Nationally Determined Contributions (Interim). Dhaka: Ministry of Environment, Forest and Climate Change, Government of the People's Republic of Bangladesh.

MoFA. 2018. Climate Change Profile: Bangladesh. Ministry of Foreign Affairs, Government of the People's Republic of Bangladesh.
Molino, Grace D., Melissa A. Kenney, and Ariana E. SuttonGrier. 2020. "Stakeholder-defined scientific needs for coastal resilience decisions in the Northeast U.S." Marine Policy.

https://doi.org/10.1016/j.marpol.2020.103987

Mondal, M. Shahjahan, Mohammad Towheedul Islam, Debanjali Saha, Muhammad Shahriar Shafayet Hossain, Prodip Kumar Das, and Rezaur Rahman. 2019. "Agricultural adaptation practices to climate change impacts in coastal Bangladesh." Springer 7-21. https://doi.org/10.1007/978-3-030-05237-9_2

Nelson, D. R., B. P. Bledsoe, S. Ferreira, and N. P Nibbelink. 2020. "Challenges to realizing the potential of naturebased solutions. In Current Opinion in Environmental Sustainability." Elsevier B.V. https://doi.org/10.1016/j.cosust.2020.09.001

Pauleit, S., T. Zölch, R. Hansen, T.B. Randrup, and C.K van den Bosch. 2017. "Nature-based solutions and climate change-four shades of green." Nature-Based Solutions to Climate Change Adaptation in Urban Areas. Theory and Practice of Urban Sustainability Transitions. Springer, Cham. https://doi.org/10.1007/978-3-31956091-5 3

Reza, Ahm Ali, and Md. Kamrul Hasan. 2019. "Forest Biodiversity and Deforestation in Bangladesh: The Latest Update." In Forest Degradation Around the World, by Mohd Nazip Suratman. IntechOpen. https://doi.org/10.5772/intechopen.86242

Rezaie, Ali Mohammad, Celso M. Ferreira and Mohammad Rezaur Rahman. 2019. "Storm surge and sea level rise: Threat to the coastal areas of Bangladesh." In Extreme Hydroclimatic Events and Multivatiate Hzazards in a Changing Environment, 438. Elsevier. https://doi.org/10.1016/B978-0-12-814899$\underline{0.00013-4}$

Rezaie, Ali Mohammad, Jarrod Loerzel, and Celso M. Ferreira. 2020. "Valuing natural habitats for enhancing coastal resilience: Wetlands reduce property damage from storm surge and sea level rise." PLOS ONE.

https://doi.org/10.1371/journal.pone.0226275

Seddon, Nathaile, Alison Smith, Pete Smith, Isabel Key, Alexandre Chausson, Cecile Girardin, Jo House, Shilpi Srivastava, and Beth Turner. 2021. "Getting the message right on nature-based solutions to climate change." Global Change Biology (Global) 1-29. https://doi.org/10.1111/gcb.15513

Seddon, Nathalie, Alexandre Chausson, Pam Berry, Cécile A. J. Girardin, Alison Smith, and Beth Turner. 2020. "Understanding the value and limits of nature-based solutions to climate change and other global challenges." Royal Society. https://doi.org/10.1098/rstb.2019.0120 
Tasnim, Tasfia, Farah Anzum, Haseeb Md. Irfanullah, Nathalie Seddon, and Saleemul Huq. 2020. A Roadmap for Nature-based Solutions in Bangladesh: Promises and Challenges. December 2. Accessed December 24, 2020. http://www.nbsbangladesh.info/news/policybrief-on-a-roadmap-for-nbs-in-bangladesh/.

USAID. 2013. Bangladesh Climate Vulnerability Profile. USAID.
World Bank. 2018. Nature-based Solutions for Disaster Risk Management. World Bank Group.

Zongo, Bilasse, Frédéric Zongo, Aboubacar Toguyeni, and Joseph I. Boussim. 2017. "Water quality in forest and village ponds in Burkina Faso (western Africa)." Journal of Forestry Research. https://doi.org/10.1007/s11676-017-0369-8

Samina Islam is currently working as a Junior Research Officer at the International Centre for Climate Change and Development. Her research interest is in human security and rights with special focus on climate change policies, sustainable development, and climate-induced migration and displacement. Samina plans to pursue a master's degree to enhance her knowledge and research skills around the nexus between human rights and climate change and their placement in the policy sphere.

Farah Anzum is an independent researcher from Bangladesh. Her interest lies in the field of environmental management and policies, ecosystem services, and climate finance. She has more than three and a half years of working experience with local communities, policymakers, and academicians. She has published more than twelve articles related to environmental issues, climate finance, and nature-based solutions.

Adiba Bintey Kamal works as a project associate at the International Centre for Climate Change and Development. She holds a master's degree in development studies. Her research interest lies in nature-based solutions, adaptation, community-based adaptation, climate finance, and gender.

Mahmuda Akter has around four years of working experience in the research sectors of Bangladesh. Currently, she is a Research Officer of the International Centre for Climate Change and Development. Her research interest lies in climate change adaptation, capacity building, migration, and urban development. Her M.Sc. in Disaster Management was from the prestigious Dhaka University (Dhaka, Bangladesh), and her B.Sc. in Environmental Management was from Independent University (Dhaka, Bangladesh).

Ali Mohammad Rezaie is the Research Coordinator at the International Centre for Climate Change and Development and a Graduate Research Fellow at Virginia Sea Grant (Gloucester Point, VA, USA). He holds a Ph.D. in Civil, Infrastructure and Environmental Engineering from George Mason University (Fairfax, VA, USA). His recent research focuses on how nature-based solutions and ecosystem services can address the impacts of natural disasters and climate change and enhance societal resilience.

Mizan R. Khan has a Ph.D. in Environmental Policy and Management from the University of Maryland School of Public Policy (College Park, MD, USA). He is currently Deputy Director at the International Centre for Climate Change and Development. Dr. Khan's recent research and publications include three books: "Toward a Binding Climate Change Adaptation Regime: A Proposed Framework" (Routledge, 2014), "Power in a Warming World: The New Politics of Climate Change and the Remaking of Environmental Inequality" (MIT Press, 2015), and “The Paris Framework for Climate Change Capacity Building” (Routledge, 2018). 